\title{
Effects of dietary lipids on renal function of aged rats
}

C. Valente Gamba,

A. Zeraib Caraviello, A. Matsushita, G.M. Alves, L. N unes da Silva,

G. Nascimento Gomes and F. Zaladek Gil

\author{
Disciplina de Fisiologia Renal e Termometabologia, \\ Escola Paulista de Medicina, Universidade Federal de São Paulo, \\ São Paulo, SP, Brasil
}

\section{Correspondence}

F. Zaladek Gil

Disciplina de Fisiologia Renal e Termometabologia, EPM, UNIFESP Rua Botucatu, 862, $5^{\circ}$ andar 04023-900 São Paulo, SP Brasil

Fax: +55-11-575-9165

E-mail: frida@ecb.epm.br

Research supported by FAPESP. ......................

Received June 12, 2000 Accepted December 6, 2000

\section{Abstract}

Normal aging is accompanied by renal functional and morphological deterioration and dietetic manipulation has been used to delay this age-related decline. We examined the effects of chronic administration of diets containing $5 \%$ lipid-enriched diet (LD, w/w) on renal function of rats at different ages. Three types of LD were tested: canola oil, fish oil and butter. Mean systemic tail-cuff blood pressure and glycemia remained within the normal range whatever the age and the diet of the animals. Proteinuria began to rise from the 8 th month in the groups ingesting LD, while in the control group it increased significantly (above $10 \mathrm{mg} / 24 \mathrm{~h}$ ) only after the 10th month. With age, a significant and progressive decline in glomerular filtration rate (GFR) and renal plasma flow was observed in the LD groups but after 6 months of lipid supplementation, the decline in these parameters was more marked in the butter and fish oil groups. By the 18th month, the lowest GFR level was observed in the group ingesting the butter diet $\left(2.93 \pm 0.22\right.$ vs $5.01 \pm 0.21 \mathrm{ml} \mathrm{min}^{-1} \mathrm{~kg}^{-1}$ in control, $\left.\mathrm{P}<0.05\right)$. Net acid excretion, evaluated in 9- and 18-month-old rats, was stimulated in the fish oil group when compared both to control and to the other two LD groups. These results suggest that even low levels of LD in a chronic nutritional regimen can modify the age-related changes in renal function and that the impact of different types of lipid-supplemented diets on renal function depends on the kind of lipid present in the diet.
Key words

- Aging

- Lipids

- Proteinuria

- Renal function

- Acid excretion

- Canola oil

- Fish oil
Aging is associated with loss of renal mass which, by itself, has little impact on overall renal function but may increase the vulnerability of the kidney to other injuries. Structural changes include progressive renal sclerosis with glomerulosclerosis and interstitial fibrosis $(1,2)$. Among several interventions performed in order to delay the progression of the age-related decline in renal function $(3,4)$, dietetic manipulation has emerged as one of the most frequently investigated aspects. Experimentally, hypercholesterolemia has been shown to accelerate the progression of glomerular and tubular injury $(5,6)$, while lipid-lowering therapies attenuated glomerular injury in models of glomerulosclerosis. In the great majority of experimental studies, the influence of hyperlipidemia on the progression of renal injury has been evaluated in genetically obese ani- 
mals, in animals ingesting diets containing different levels of cholesterol plus cholic acid in order to induce hypercholesterolemia or in animals previously submitted to some degree of nephron injury. In the obese Zucker rat, hyperlipidemia is associated with the rapid development of glomerulosclerosis (7). Few studies have investigated the effect of long-term lipid feeding on renal function of normal aged rats. In the present study, we describe the results of a study undertaken to test the effects of chronic administration of diets containing low levels of different types of lipids on renal function of rats at different ages.

Twelve-week-old EPM1 Wistar rats weighing 250 to $320 \mathrm{~g}$ were fed a granular commercial feed (Nuvilab Ltda., Curitiba, PR, Brazil) and maintained with alternating 12-h cycles of light and darkness at a constant temperature of $25^{\circ} \mathrm{C}$. The animals were housed in individual cages and were randomly assigned to four groups of 10 rats each, studied at 6, 9 and 18 months. Rats in the experimental groups consumed a $5 \%$ lipid-enriched diet (LD; w/w) added daily to the commercial feed. Three types of LD were tested: canola oil, fish oil, and butter. Canola oil is characterized by a low concentration of saturated fatty acids (FA), a relatively high concentration of monosaturated FA (predominantly oleic acid), and a moderate amount of linoleic and linolenic acid. Fish oil has a unique FA composition with an appreciable amount of $\omega-3$ polyunsaturated fatty acids (PUFAs), eicosapentaenoic acid and docohexaenic acid but a small amount of $\omega-6$ PUFA linoleic acid, the main constituent of vegetable oil $(8,9)$. $\omega$-3 PUFAs are the precursors of less inflammatory series of prostanoids than $\omega-6$ PUFAs. Butter was used because of its richness in saturated FA. The control diet had about $10 \%$ fewer calories than the fat-supplemented diets. The food intake of the LD rats was matched to that of the control group on a weight basis.

Body weight was recorded weekly. Sys- tolic arterial pressure was measured indirectly by tail plethysmography every 4 weeks. In all groups glomerular filtration rate (GFR) and renal plasma flow were determined by measuring inulin and para-aminohippurate clearance, respectively. Acid excretion (AE) was calculated by the following formula: $\mathrm{AE}$ $=\mathrm{TA}+\mathrm{NH}_{4}-\mathrm{C}_{\mathrm{HCO}_{3}}$, where TA is titratable acidity (measured by microtitration with 0.01 $\mathrm{N} \mathrm{NaOH}), \mathrm{NH}_{4}$ is the ammonium excretion, measured by a colorimetric method, and $\mathrm{C}_{\mathrm{HCO}_{3}}$ is the amount of bicarbonate excreted in urine, calculated with a blood gas analyzer (model 248, Ciba-Corning, Halstead, England). Twenty-four-hour urine collection was performed with rats housed in metabolic cages and allowed free access to water. Proteinuria was measured from 3 months on every 4 weeks. Data are expressed as the mean \pm SEM. Statistical analysis was performed by analysis of variance followed by the Scheffé test; for all analyses the null hypothesis rejection level was set at 0.05 .

Mean systemic tail-cuff blood pressure and glycemia remained within the normal range whatever the age and the diet of the animals. Irrespective of age, serum cholesterol levels were significantly decreased in the fish oil group compared to the control, butter and canola oil groups. Serum triglyceride levels in fish oil and canola oil rats were similar and were significantly lower than serum triglyceride in the control and butter groups. No age-dependent significant difference was obtained in the relative weight of the kidneys of rats that ingested different LD when compared to the control group ( 0.36 to $0.42 \mathrm{~g}$ kidney/100 g body weight). The initial increase in body weight was similar in all groups but from the 16th week until the end of the experiment, LD caused an additional $10 \%$ increase in this parameter, as shown in Figure 1. As also shown in the figure, proteinuria began to rise from the 8 th month in LD groups while in the control group it was not before 10th month that proteinuria was observed at significant lev- 
els, a result that agrees with previous data obtained by Anderson et al. (3) for male Munich-Wistar rats. These results suggest that the chronic ingestion of additional amounts of lipid, even at a low level and whatever the type, can trigger some degree of nephron injury.

As shown in Table 1, at 9 months of age, we observed a decline in GFR and renal plasma flow in the animals which ingested the lipid-rich diets, and in 18-month-old rats, the fish oil and butter groups showed a significant decrease in those parameters when compared to the control group at the same age; if corrected for kidney weight, these differences were still present; for example, GFR was $1.95 \pm 0.11$ in controls, $0.95 \pm 0.04$ in the butter group, $1.04 \pm 0.17$ in the fish oil group and $1.33 \pm 0.29 \mathrm{ml} \mathrm{min}^{-1} \mathrm{~g}^{-1}$ in the canola oil group, confirming that the agedependent decline in renal function was accelerated by the ingestion of LD. The complex mechanism by which lipids aggravate renal diseases is not well understood. Factors such as intraglomerular macrophage infiltration, increased glomerular capillary pressure and the degree of lipoprotein oxidation have been claimed to be major determinants of the progression of glomerulosclerosis (5-7). However, the controversy about the effects of different types of lipid-rich
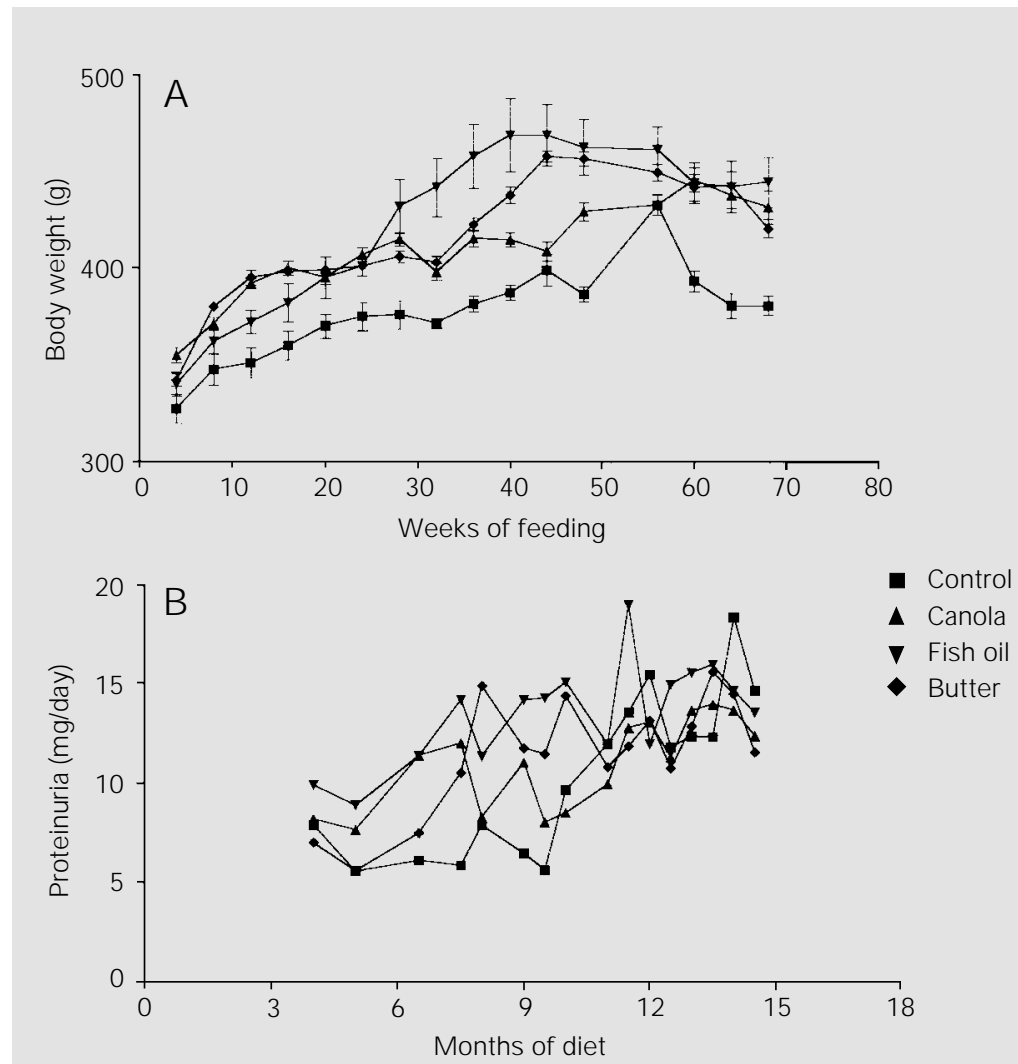

Figure 1 - Panel A, Body weight of rats fed a stock diet and supplemented with different lipid-enriched diets (LD). The animals were 12 weeks old at the beginning of the experiment. From the 16th week until the end of the experiment, the mean body weight of rats fed the LD tended to be about $10 \%$ higher than that of control animals. Panel B, Serial values for 24-h proteinuria in control and LD rats. Rats fed the LD developed progressive proteinuria from 8 months until the end of the experiment. Control rats developed proteinuria from 10 months on.

Table 1 - Mean values of renal function data for 6-, 9- and 18-month-old rats treated with different lipid-enriched diets.

GFR, Glomerular filtration rate; RPF, renal plasma flow; $\mathrm{AE}$, net acid excretion. Results are reported as means $\pm \mathrm{SEM} ; \mathrm{N}=18$ for all groups. *P<0.05 vs control; +vs canola; " VS fish oil; \$V the same LD group at 9 months of age (analysis of variance followed by the Scheffé test).

\begin{tabular}{|c|c|c|c|c|c|c|c|c|c|}
\hline & \multicolumn{3}{|c|}{ GFR (ml min-1 $\left.\mathrm{kg}^{-1}\right)$} & \multicolumn{3}{|c|}{$\operatorname{RPF}\left(\mathrm{ml} \mathrm{min}{ }^{-1} \mathrm{~kg}^{-1}\right)$} & \multicolumn{3}{|c|}{$\mathrm{AE}\left(\mu \mathrm{Eq} \mathrm{min} \mathrm{n}^{-1} \mathrm{~kg}^{-1}\right)$} \\
\hline & 6 months & 9 months & 18 months & 6 months & 9 months & 18 months & 6 months & 9 months & 18 months \\
\hline Control & $6.40 \pm 0.45$ & $5.88 \pm 0.31$ & $5.01 \pm 0.21$ & $17.22 \pm 0.93$ & $19.30 \pm 1.20$ & $13.28 \pm 0.61^{\$}$ & $5.25 \pm 0.36$ & $4.45 \pm 0.232$ & $2.29 \pm 0.14 \$$ \\
\hline Canola & $4.45 \pm 0.18$ & $4.72 \pm 0.30$ & $4.31 \pm 0.43^{*}$ & $13.53 \pm 0.44$ & $14.92 \pm 0.97$ & $12.16 \pm 0.74$ & $3.32 \pm 0.24$ & $3.33 \pm 0.32 *$ & $2.36 \pm 0.14 \$$ \\
\hline Fish oil & $4.35 \pm 0.25$ & $4.30 \pm 0.34^{*}$ & $3.09 \pm 0.18^{* \$}$ & $15.79 \pm 0.79$ & $13.26 \pm 1.43^{*}$ & $11.17 \pm 0.81$ & $4.41 \pm 0.28$ & $5.49 \pm 0.27^{*+}$ & $4.36 \pm 0.23$ \\
\hline Butter & $4.42 \pm 0.28$ & $4.50 \pm 0.31^{*}$ & $2.93 \pm 0.22^{*+\$}$ & $12.30 \pm 0.49 *$ & $14.88 \pm 1.27$ & $9.27 \pm 0.65^{*+\$}$ & $3.36 \pm 0.31$ & $3.17 \pm 0.26^{* \#}$ & $2.58 \pm 0.13^{\$}$ \\
\hline
\end{tabular}


In a study by Ingram et al. (10) the authors showed that supplementation with flax oil (which is rich in $\alpha$-linolenic acid) to rats subjected to $5 / 6$ nephrectomy slowed the renal injury. Fish oil supplements have been advocated to have beneficial effects in IgA nephropathy (11), diabetic nephropathy (12) and in a model of subtotal renal ablation (13). In contrast, one study using the remnant model of experimental renal injury has demonstrated a deleterious effect of fish oil administration on renal structure and function (14), and in a clinical study, $\omega-3$ supplementation was unable to reduce lipoprotein concentration in patients with chronic glomerular disease (15). The present data suggest that fish oil supplementation not only was unable to protect against the natural age-induced modification in renal hemodynamics but accelerated the decline in glomerular function to the same extent as butter did, a result suggesting that the physiopathology of the decline of renal function observed during aging differs from that triggered in models of renal ablation, in which clear benefits were demonstrated concerning glomerular hemodynamics. In fact, Schmitz et al. (13) observed a $15 \%$ reduction in mean arterial pressure in nephrectomized rats treated with $17 \% \omega-3$ when compared to untreated animals and suggested that, collectively, the hemodynamic effects were similar to those obtained after angiotensin II blockade. Although in our study mean arterial pressure was maintained at normal levels throughout the experimental period, it is important to remember that young and old rats respond differently to vasomodulating substances such as eicosanoids.

In young adults, renal hemodynamics is not controlled by eicosanoids but with age it becomes dependent on vasodilatory prostaglandins (PG) and the renal vasoconstrictor effect of thromboxane $\mathrm{A}_{2}$ may be accentuated (16). In our study, $\omega-3$ was given in a low-dose regimen $(5 \%)$ which may have been insufficient to protect the kidney against the vasoconstrictor stimulus. However, the effect of age and the type of diet on the tubular ability of acid excretion deserves attention. In 9-monthold control rats, as expected, acid excretion was maintained at the level of that observed at 6 months of age; however, both the canola oil and butter groups showed a significant decline in this parameter while a stimulus in acid excretion was shown in the fish oil group at that age, which persisted until 18 months. In all the other 18-month-old rats, including the control group, a decline in acid excretion was observed. It is accepted that the aged kidney can maintain the acid-base balance under normal conditions, but not when subjected to an acid load. Among several factors that can impair the secretion of $\mathrm{H}^{+}$, the decreased availability of $\mathrm{Na}^{+}-\mathrm{K}^{+}$-ATPase in the basolateral membrane of the tubular cells (17) and the decreased ability of ammonium excretion (18) have been demonstrated in the aged kidney. On the other hand, PG are one of several factors that can influence renal ammoniagenesis; since $\omega-3$ ingestion is able to affect renal PG synthesis and membrane fluidity, it is not unexpected that chronic consumption of a fish oil diet could interfere with ammonium excretion and consequently with acid excretion. This is the first report of the effect of long-term LD feeding on the ability of acid excretion which was stimulated in the fish oil group due to a significant increase in the ammonium component, while titratable acidity remained unchanged.

In MDCK cells, $\mathrm{PGE}_{2}$ has been shown to induce intracellular alkalinization via stimulation of the $\mathrm{Na}^{+}-\mathrm{H}^{+}$exchanger (19), while in vivo experiments in rats have demonstrated that PG were able to inhibit renal ammoniagenesis (20). In fact, the influence of dietary FA intake on overall acid excretion ability has been poorly investigated and much more work is needed to clarify this point. Moreover, the present data suggest that different types of LD can have different repercussions on glomerular and tubular function, a fact that may be useful in the management of several kinds of nephropathies. 


\section{References}

1. Baylis C, Fredericks M, Leypoldt J , Frigon R, Wilson C \& Henderson L (1988). The mechanism of proteinuria in aging rats. Mechanisms of Ageing and Development, 45: 111-126.

2. De La Cruz IC, Ruiz-Torres $P$, Del Moral RG, Rodriguez-Puyol $M$ \& RodriguezPuyol D (2000). Age-related progressive renal fibrosis in rats and its prevention with ACE inhibitors and taurine. American J ournal of Physiology, 278: F122-F129.

3. Anderson S, Rennke HG \& Zatz R (1994). Glomerular adaptations with normal aging and with long-term converting enzyme inhibition in rats. American J ournal of Physiology, 267: F35-F43.

4. Grone $H$, Walli A, Grone E, Niedmann $P$, Thiery J, Seidl D \& Helmchen U (1989). Induction of glomerulosclerosis by dietary lipids; functional and morphological study in the rat. Laboratory Investigation, 60: 433-445.

5. Kasiske BL, O'Donnell P, Schmitz PG, Kim Y \& Keane WF (1990). Renal injury of dietinduced hypercholesterolemia in rats. Kidney International, 37: 880-891.

6. Scheuer H, Gwinner W, Hohbach J, Grone $E F$, Brandes RP, Malle E, Olbricht CJ, Walli AK \& Grone HJ (2000). Oxidant stress in hyperlipidemia-induced renal damage. American J ournal of Physiology, 278: F63-F74.

7. Lavand $S$, Michel $O$, Sassy-Pringent $C$, Heudes D, Bazin R, Bariety J \& Chevalier $J$ (1996). Early influx of glomerular macro- phages precedes glomerulosclerosis in the obese Zucker rat model. J ournal of the American Society of Nephrology, 7: 2604-2615.

8. MCDonald BE, Gerrard J M, Bruce VM \& Corner EJ (1989). Comparison of the effect of canola oil and sunflower oil on plasma lipids and lipoproteins and on in vivo thromboxane $A 2$ and prostacyclin production in healthy young men. American J ournal of Clinical Nutrition, 50: 13821388.

9. Narisawa T, Fukuaura $\mathrm{Y}$, Yasawa K, Ishikawa C, Isoda Y \& Nishizawa Y (1994). Colon cancer prevention with a small amount of dietary perilla oil high in alphalinolenic acid in an animal model. Cancer, 73: 2069-2075.

10. Ingram AJ , Parbtani A, Clarck WF, Spanner E, Keeney M, Chin Yee I, Philbrick DJ \& Holub BJ (1990). Effects of flaxseed and flax oil diets in a rat $5 / 6$ renal ablation model. American J ournal of Kidney Diseases, 25: 320-329.

11. Dillon JJ (1997). Fish oil therapy for IgA nephropathy: Efficacy and interstudy variability. J ournal of the American Society of Nephrology, 8: 1739-1744.

12. McCarty MF (1998). A central role for protein kinase $\mathrm{C}$ overactivity in diabetic glomerulosclerosis: Implications for prevention with antioxidants, fish oil and ACE inhibitors. Medical Hypotheses, 50: 155165.

13. Schmitz PG, Lane PL, Dalal R, Zhang K \&
Majidi B (1995). $\omega$-3 fatty acids attenuate glomerular capillary hydraulic pressure in rats with renal ablation. Kidney International, 48: 1792-1800.

14. Sharschmidt L, Gibbons N \& McGarry L (1987). Effects of dietary fish oil on renal insufficiency in rats with subtotal nephrectomy. Kidney International, 32: 700-709.

15. Lenzi S, Caprioli R, Rindi P, Lazzerini G, Bernini W, Pardini E, Luchetti A, Galli C, Carr L \& Caterina R (1996). Omega-3 fatty acid supplementation and lipoprotein concentration in patients with chronic glomerular diseases. Nephron, 72: 383-390.

16. Menconi $M$, Taylor L, Martin B \& Polgar P (1987). Prostaglandins, aging and blood vessels. A review. J ournal of the American Geriatrics Society, 35: 239-247.

17. Eiam OS \& Sabatini S (1999). Age-related changes in renal function, membrane protein metabolism and $\mathrm{Na}^{+}-\mathrm{K}^{+}$-ATPase activity and abundance in hypokalemic F344xBNF(1) rats. Gerontology, 45: 254264.

18. Lubran MM (1995). Renal function in the elderly. Annals of Clinical and Laboratory Science, 25: 122-133.

19. Rodriguez MG \& Reyes J L (1995). Induction of alkalinization in cultured renal cells (MDCK line) by prostaglandin $\mathrm{E}_{2}$. Prostaglandins, 49: 79-91.

20. J ones ER, Beck TR, Kapoor S, Shay R \& Narins RG (1984). Prostaglandins inhibit renal ammoniagenesis in the rat. J ournal of Clinical Investigation, 74: 992-1002. 